\title{
CORRIGENDUM
}

\section{Multicolored stain-free histopathology with coherent Raman imaging}

Christian W Freudiger, Rolf Pfannl, Daniel A Orringer, Brian G Saar, Minbiao Ji, Qing Zeng, Linda Ottoboni, Wei Ying, Christian Waeber, John R Sims, Philip L De Jager, Oren Sagher, Martin A Philbert, Xiaoyin Xu, Santosh Kesari, X Sunney Xie and Geoffrey S Young

Laboratory Investigation (2012) 92, 1661; doi:10.1038/labinvest.2012.139

Correction to: Laboratory Investigation (2012); doi: 10.1038/ labinvest.2012.109; advance online publication, 20 August 2012.
In this article, the name of the eighth author is incorrect. The correct name is Ying Wei. 